\title{
Impact of Malignancies in the Early and Late Time Course of Takotsubo Cardiomyopathy
}

\author{
Mélanie Girardey, MD; Laurence Jesel, MD; Umberto Campia, MD; Nathan Messas, MD; \\ Sébastien Hess, MD; Alessio Imperiale, MD, PhD; Cyrille Blondet, MD; Annie Trinh, MD; \\ Patrick Ohlmann, MD, PhD; Olivier Morel, MD, PhD
}

\begin{abstract}
Background: Although the relationship between malignancies and catecholamine-induced myocardial stunning remains largely speculative, it has been suggested that the presence of cancer may lower the threshold for stress stimuli and/or may aggravate cardiac adrenoreceptor sensitivity. We sought to investigate whether associations exist between a previous or current diagnosis of malignancy, diagnostic parameters during hospitalization and death in takotsubo.
\end{abstract}

\begin{abstract}
Methods and Results: The 154 takotsubo patients were retrospectively identified between May 2008 and December 2014. Previous history of malignancy was identified in 44 patients (28.5\%). Cardiac arrest was present at admission in 13 patients (8.4\%). Intra-aortic balloon pump was inserted in 16 patients $(10.4 \%)$. In patients with malignancy, higher B-type natriuretic peptide (BNP), leukocyte and C-reactive protein (CRP) peaks could be observed during the hospital phase. Initial impairment of left ventricular ejection fraction was negatively related to BNP, leukocyte, and CRP peaks. At a median follow-up of 364 days, all-cause death occurred in 41 patients (26.6\%) and cardiac death in 12 patients (7.7\%). Multivariate Cox regression analysis identified malignancy (hazard ratio 4.77 (1.02-22.17), leukocyte peak and age as independent predictors of cardiac death. Malignancy $(2.62(1.26-5.44)$, leukocyte peak (1.05 (1.01-1.08) and initial cardiac arrest (6.68 (2.47-18.01) were identified as independent predictors of overall mortality.
\end{abstract}

Conclusions: In the present takotsubo patients, the prevalence of malignancy was high and may have affected cardiovascular outcomes through the activation of inflammatory and neurohormonal mechanisms. (Circ J 2016; 80: 2192-2198)

Key Words: Inflammation; Malignancy; Mortality; Takotsubo cardiomyopathy

$\mathbf{T}$ akotsubo cardiomyopathy can be broadly defined as a transient cardiomyopathy clinically sharing many features of myocardial infarction such as acute chest pain, ECG changes and troponin rise. Various sets of criteria have been proposed over time to standardize the diagnosis of takotsubo cardiomyopathy. ${ }^{1,2}$ Although no definitive agreement has been achieved, the presence of mostly reversible regional wall motion abnormalities that extend beyond a single epicardial vascular distribution and occurring in the absence of hemodynamically significant coronary obstructions appears to be the unifying feature. ${ }^{2,3}$

A large body of evidence indicates that takotsubo cardiomyopathy tends to occur more frequently in women, in older patients, and in the presence of a history of emotional or physical stress. ${ }^{4}$ Intriguingly, the prevalence of cancer history or new diagnosis appears to be higher in patients with takotsubo cardiomyopathy compared with age-matched populations. ${ }^{5-7}$ As takotsubo cardiomyopathy has been reported in association with several other clinical scenarios, such as epinephrine treatment or overdosing, trauma, acute medical or surgical illnesses such as shock and intracranial bleeding, and pheochromocytoma, ${ }^{8}$ a common pathophysiological mechanism involving the catecholaminergic system has been postulated.,,9-11 Although the relationship between malignancies and catecholamine-induced myocardial stunning remains largely speculative, it has been suggested that the presence of cancer may lower the threshold for stress stimuli and/or may aggravate cardiac adrenoreceptor sensitivity. ${ }^{5,6}$ Whether, in patients with takotsubo cardiomy-

Received April 27, 2016; revised manuscript received July 12, 2016; accepted July 28, 2016; released online September 1, 2016 Time for primary review: 18 days

Cardiology Department (M.G., L.J., N.M., S.H., A.T., P.O., O.M.), Radiology Department (A.I., C.B.), Nouvel Hôpital Civil, University Hospital, University of Strasbourg, Strasbourg, France; MedStar Heart and Vascular Institute, MedStar Washington Hospital Center, Washington, DC (U.C.), USA; and UMR CNRS 7213, Pharmacy Department, University of Strasbourg, Illkirch (O.M.), France

Mailing address: Olivier Morel, Professor, MD, PhD, Pôle d'Activité Médico-Chirurgicale Cardiovasculaire, Nouvel Hôpital Civil, Hôpitaux Universitaires de Strasbourg, 1 place de l’Hôpital, 67091 Strasbourg, France. E-mail: olivier.morel@chru-strasbourg.fr

ISSN-1346-9843 doi:10.1253/circj.CJ-16-0388

All rights are reserved to the Japanese Circulation Society. For permissions, please e-mail: cj@j-circ.or.jp 


\begin{tabular}{lccc}
\hline \multicolumn{1}{l}{ Table 1. Clinical Characteristics of Takotsubo Patients } & & \\
\cline { 2 - 3 } & \multicolumn{2}{c}{ Takotsubo cardiomyopathy } & P value \\
Patients, $\mathbf{n}$ & 110 & With malignancy & \\
Age (years) & $67 \pm 13$ & 44 & 0.571 \\
Female & $90(81.8)$ & $68 \pm 10$ & 0.033 \\
Arterial hypertension & $73(66.4)$ & $29(65.9)$ & 0.032 \\
Diabetes mellitus & $29(26.4)$ & $21(47.7)$ & 0.442 \\
Hyperlipidemia & $45(10.9)$ & $9(20.5)$ & 0.113 \\
Past tobacco use & $22(20)$ & $12(27.3)$ & 0.033 \\
Current tobacco use & $26(23.6)$ & $16(36.4)$ & 0.904 \\
Obesity & $25(22.7)$ & $10(22.7)$ & 0.108 \\
Presentation & & $5(11.4)$ & \\
Chest pain & $48(43.6)$ & & 0.570 \\
Dyspnea & $42(38.2)$ & $17(38.6)$ & 0.035 \\
Cardiac arrest & $10(9.1)$ & $25(56.8)$ & 0.647 \\
Syncope & $4(3.6)$ & $3(6.8)$ & 0.666 \\
IABP insertion & $12(10.9)$ & $1(2.3)$ & 0.726 \\
Amines & $12(10.9)$ & $4(9.1)$ & 0.439 \\
Dobutamine & $5(4.5)$ & $3(6.8)$ & 0.510 \\
Adrenaline & $4(3.6)$ & $1(2.3)$ & 0.666 \\
Noradrenaline & $11(10)$ & $1(2.3)$ & 0.535 \\
Emotional trigger & $23(20.9)$ & $3(6.8)$ & 0.011 \\
Physical stressor & $48(43.6)$ & $5(11.4)$ & 0.011 \\
Trigger unknown & $39(35.5)$ & $31(70.5)$ & 0.011 \\
\hline ABP intra-aortic & & $8(18.2)$ & \\
\hline
\end{tabular}

IABP, intra-aortic balloon pump.

opathy, the presence of cancer correlates with worse ECG, and echocardiographic, and laboratory parameters at the time of presentation, and whether these variables predict all-cause and cardiac death in this population has not been explored. Therefore, the current study was designed to investigate whether associations exist between a previous or current diagnosis of malignancy, diagnostic parameters during hospitalization and death in patients with takotsubo cardiomyopathy.

\section{Methods}

\section{Study Population}

Patients with suspected takotsubo cardiomyopathy were identified from the 21,326 coronary angiograms recorded in the Cardiac Catheterization Laboratory database of the University Hospital of Strasbourg between May 2008 and December 2014. The database was queried using the key words "stress", "takotsubo" or "catecholamine". The diagnosis of takotsubo cardiomyopathy was made according to the Madias' criteria. ${ }^{3}$ However, given the common underlying mechanism, we did not exclude patients with pheochromocytoma and intracranial bleeding. Patients with coronary stenosis $>50 \%$ were included when transient left ventricular (LV) dysfunction could not be explained by transient or permanent coronary occlusion. Exclusion criteria comprised a diagnosis of acute coronary occlusion, percutaneous intervention, myocarditis, valve replacement during the hospital phase, and tachycardia-induced cardiomyopathy. Two cardiologists (M.G. and O.M.) reviewed all the cases and the diagnosis of takotsubo cardiomyopathy was made based on a consensus agreement after exclusion of other reversible causes of myocardial dysfunction (eg, myocarditis, tachycardia-induced cardiomyopathy). The study protocol was approved by the Institutional Review Board of the University of Strasbourg. Retrospective consent was obtained from patients when alive at follow-up or from their relatives.

\section{Clinical Assessment}

At the time of the index event, a complete medical history was recorded. Because the entire recovery of malignancy, as cure of cancer without recurrence is difficult to establish, every history of malignancy was considered. 12-lead ECG and routine laboratory data, including a quantitative troponin I (TN-I), BNP, highsensitivity C-reactive protein and leukocyte count were obtained serially. For the current study, analysis of the ECGs was performed by a cardiologist who was blind to the diagnosis of malignancy. The following parameters were collected: presence and number of Q waves, Q wave amplitude in millimeters, and sum of Q waves amplitude in millimeters. Multiplane coronary angiography was performed in all patients by radial or femoral approach using standard techniques. LV ejection fraction (EF) was calculated from planimetric evaluation of the end-diastolic and endsystolic volumes in the $30^{\circ}$ right anterior oblique projection. 2D transthoracic echocardiographic studies were performed in all patients in a standard fashion to assess LV systolic function and wall motion abnormalities. Calculation of the LVEF was done in the 4-chamber view according to Simpson's method.

\section{Clinical Follow-up}

After hospital discharge, follow-up was obtained for all patients using standardized telephone interviews with a cardiologist or another physician. In cases of death, the cause was ascertained by thorough review of all available clinical information at the time of death. Cardiac death was defined as any death with demonstrable cardiac cause or any death that was not clearly attributable to a noncardiac cause. Follow-up was stopped at 1,000 days. 


\begin{tabular}{|c|c|c|c|}
\hline & Takotsubo c & diomyopathy & P yalue \\
\hline & Without malignancy & With malignancy & r value \\
\hline \multicolumn{4}{|l|}{ Electrocardiogram } \\
\hline $\mathrm{Q}$ waves, $\mathrm{n}$ & $1.3 \pm 1.8$ & $2.1 \pm 2.1$ & 0.028 \\
\hline $\mathrm{Q}$ wave max amplitude $(\mathrm{mm})$ & $3.8 \pm 5.8$ & $6.9 \pm 7.1$ & 0.011 \\
\hline Q wave, sum of amplitudes $(\mathrm{mm})$ & $9 \pm 15$ & $17 \pm 19$ & 0.011 \\
\hline \multicolumn{4}{|l|}{ Wall motion distribution, $\mathrm{n}(\%)$} \\
\hline Apical & $66(60)$ & $30(68.2)$ & \\
\hline Apical+other location & $88(80)$ & $38(86.4)$ & \\
\hline Midventricular & $26(23.6)$ & $7(15.9)$ & \\
\hline Other & $18(16.3)$ & $7(15.9)$ & 0.628 \\
\hline \multicolumn{4}{|l|}{ Ejection fraction (\%) } \\
\hline Angiography & $37 \pm 11$ & $34 \pm 10$ & 0.161 \\
\hline Echo: initial & $38 \pm 11$ & $36 \pm 12$ & 0.465 \\
\hline Echo: at discharge & $54 \pm 10$ & $54 \pm 10$ & 0.806 \\
\hline $\begin{array}{l}\text { Echo in-hospital change } \\
\text { (discharge-initial) }\end{array}$ & $18 \pm 10$ & $21 \pm 10$ & 0.382 \\
\hline Echo: at follow-up & $62 \pm 7$ & $66 \pm 5$ & 0.162 \\
\hline Coronary stenosis $>\mathbf{5 0} \%$ & $8(7.3)$ & $3(6.8)$ & 0.921 \\
\hline \multicolumn{4}{|l|}{ Troponin I ( $\mu \mathrm{g} / \mathrm{L})$} \\
\hline On admission & $1.04(0.35-3.65)$ & $1.41(0.16-5.16)$ & 0.969 \\
\hline Peak & $3.08(1.30-7.55)$ & $5.23(0.95-12.89)$ & 0.213 \\
\hline At discharge & $0.41(0.13-1.23)$ & $0.23(0.07-0.88)$ & 0.340 \\
\hline \multicolumn{4}{|l|}{ BNP (ng/L) } \\
\hline On admission & $268(82-986)$ & $515(149-987)$ & 0.115 \\
\hline Peak & $1,001(363-1,989)$ & $1,970(950-3,836)$ & 0.014 \\
\hline At discharge & $455(133-758)$ & $450(191-1,105)$ & 0.403 \\
\hline \multicolumn{4}{|l|}{ Leukocyte count (109/L) } \\
\hline On admission & $11,460(8,240-14,850)$ & $11,000(6,765-14,487)$ & 0.560 \\
\hline Peak & $12,810(9,622-19,030)$ & $16,075(12,190-23,120)$ & 0.017 \\
\hline At discharge & $7,335(5,875-9,182)$ & $7,490(6,110-11,000)$ & 0.730 \\
\hline \multicolumn{4}{|l|}{ CRP (mg/L) } \\
\hline On admission & $10(1-28)$ & $33(9-151)$ & 0.001 \\
\hline Peak & $57(15-131)$ & $129(47-225)$ & 0.001 \\
\hline At discharge & $8(1-21)$ & $26(6-57)$ & 0.003 \\
\hline
\end{tabular}

Data are expressed as mean \pm SD or as median (25-75th interquartile range). BNP, B-type natriuretic peptide; CRP, C-reactive protein.

\section{Statistical Analysis}

Categorical variables are expressed as counts and percentages. Continuous variables are reported as mean \pm SD or as median and interquartile range (25-75th) according to their distribution. Categorical variables were compared with chi-square test or Fisher's exact test. Continuous variables were compared with Mann-Whitney test. To determine the predictors of death, Cox regression analysis was performed. Associations between malignancies and occurrence of clinical outcomes were assessed by Kaplan-Meier analysis and log-rank test. Correlations were studied using Spearman Test. All tests were 2-sided. $\mathrm{P}<0.05$ was considered significant. Calculations were performed using SPSS 17.0 for Windows (SPSS Inc, Chicago, IL, USA).

\section{Results}

A total of 190 patients were identified in the Cardiac Catheterization Laboratory database by our query. Of them, 154 met the inclusion and exclusion criteria and were included in the present analyses (Figure S1). Participants were divided into 2 groups according to the presence of a history of malignancy. Their baseline demographic and clinical characteristics are reported in Table 1. At the time of the index event, a previous history of malignancy was identified in 44 patients $(28.5 \%)$. Cardiac arrest was present at the time of admission in 13 patients (8.4\%). Intra-aortic balloon pump (IABP) was inserted in 16 patients (10.4\%). Female sex, history of arterial hypertension and emotional stress as the likely trigger event were more frequently recorded in patients without a history of malignancy, whereas the prevalence of past tobacco use and a physical trigger was higher in those with a positive cancer history.

The types of cancers are listed in Table S1 and the triggering events in Table S2. As detailed in Table 2, no differences between the 2 patient groups in initial LVEF, LVEF at hospital discharge, LVEF at follow-up or DLVEF during the hospital phase were present. The number of Q waves, maximum $\mathrm{Q}$ wave amplitude and sum of $\mathrm{Q}$ wave amplitudes were higher when a diagnosis of malignancy was present. The distribution of the various forms of takotsubo cardiomyopathy (apical, midventricular, and other types) was not substantially different between 
the 2 subsets of patients. Laboratory parameters during the hospital phase are reported in Table 2 . Whereas no differences in baseline BNP and leukocyte count could be observed between groups, higher peak of BNP and leukocyte count were observed in takotsubo cardiomyopathy patients with malignancy. Likewise, baseline, peak and discharge CRP levels were higher in the malignancy subgroup. TN-I peak tended to be higher in the malignancy subgroup but the difference did not reach statistical significance. The initial LVEF was inversely related to peak BNP level $(\mathrm{r}=-0.374 ; \mathrm{P}<0.001)$, leukocyte peak $(\mathrm{r}=-0.237 ; \mathrm{P}=0.005)$ and $\mathrm{CRP}$ peak $(\mathrm{r}=-0.223 ; \mathrm{P}=0.013)$. Conversely, no significant relationship between peak TN-I and initial LVEF was present $(\mathrm{r}=-0.065 ; \mathrm{P}=0.455)$.

\section{Clinical Outcomes}

Outcomes were available for all patients with a median followup of 364 days (range, 79-878). Death from any cause occurred in 41 patients $(26.6 \%)$ and cardiac death in 12 patients $(7.7 \%)$. Death occurred during hospitalization in 25 patients $(16.2 \%)$ and after hospital discharge in 16 patients $(10.3 \%)$. No recurrence of takotsubo cardiomyopathy was observed. At followup, both all-cause death and cardiac death were higher in the subgroup with malignancy compared with patients without ( $45.5 \%$ vs. $19.1 \%$; log-rank $\mathrm{P}=0.001$ and $13.6 \%$ vs. $5.5 \% \log$ rank $\mathrm{P}=0.052$ ) (Figures $\mathbf{A}, \mathbf{B})$. No effect of the type of stress on clinical outcome could be evidenced.

\section{Predictors of Cardiac Death}

By univariate Cox analysis, age, cardiac arrest at admission, IABP, history of malignancy, TN-I peak, leukocyte peak, and CRP peak were associated with cardiac death. In contrast, the type of takotsubo cardiomyopathy (apical vs. other forms), initial LVEF dysfunction, and the type of triggering event (mental vs. physical) did not correlate with death. On multivariate Cox regression analysis, cardiac arrest, history of malignancy, leukocyte count peak, and age remained as independent predictors of cardiac death (Table 3 ).

\section{Predictors of All-Cause Death}

By univariate Cox analysis, cardiac arrest at the time of admission, IABP, initial LVEF, history of malignancy, troponin peak, BNP peak, leukocyte peak, CRP peak and physical stressor were significant predictors of all-cause death. In contrast, the type of takotsubo cardiomyopathy did not correlate with death. On multivariate Cox regression analysis, cardiac arrest, history of malignancy, and leukocyte count peak remained as independent predictors of all-cause death (Table 4).

\section{Discussion}

The main findings of the present study are that, among patients presenting with takotsubo cardiomyopathy, those with a diagnosis of malignancy showed more marked ECG abnormalities; higher peak BNP and leukocyte levels, higher CRP on admission, at peak, and at discharge, and higher mortality rate. Furthermore, a diagnosis of malignancy was an independent predictor of cardiac and all-cause deaths. Thus, malignancies appear to significantly enhance neurohormonal activation and the inflammatory response during the acute phase of takotsubo cardiomyopathy and to be an independent predictor of early cardiac death and overall mortality during follow-up. In addition, our data confirm the high prevalence of malignancy in patients with this condition.

A number of clinical and experimental studies have inves-

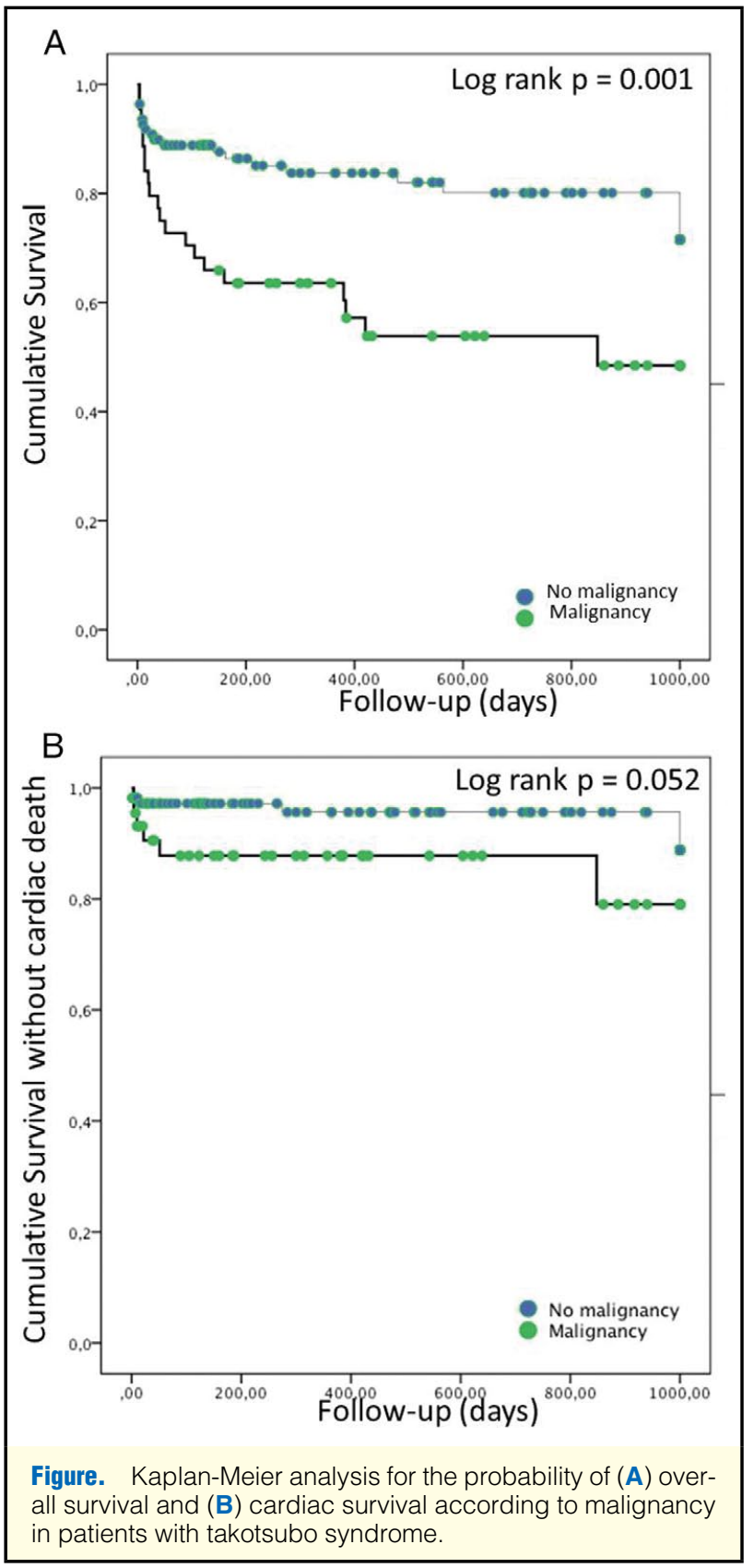

tigated the potential links between cancer, emotional stress, inflammation, and neurohormonal activation, particularly with regard to the sympathetic nervous system. ${ }^{5,6}$ The enhanced catecholamine release observed in various cancers may promote myocardial stunning, as suggested by the evidence of reversible cardiac dysfunction in pediatric patients with neuroblastoma, a primitive neural tumor often associated with elevated plasma catecholamine levels. ${ }^{12,13}$ Of interest, Lyon and coworkers have proposed that the effects of catecholamines on myocardial function are induced by a switch in the $\beta_{2}$-adrenergic receptor $\left(\beta_{2}-\mathrm{AR}\right)$ intracellular signaling from a $\mathrm{G}_{\mathrm{s}}$ to $\mathrm{G}_{\mathrm{i}}$ protein. ${ }^{10}$ Although this switch may be cardioprotective by reducing the proapoptotic effects of excessive $\beta 1$-AR stimulation of the myocardium, it may also exert negative inotropic effects. Of note, inflammation may lead to activation of p38 mitogenactivated protein kinase, ${ }^{14}$ a downstream effector of the $\beta_{2}$-AR 


\begin{tabular}{|c|c|c|c|c|c|c|}
\hline & HR & $95 \% \mathrm{Cl}$ & $P$ value & HR & $95 \% \mathrm{Cl}$ & $P$ value \\
\hline Age & 1.05 & $0.99-1.10$ & 0.065 & 1.11 & $1.03-1.2$ & 0.006 \\
\hline Female & 0.82 & $0.22-3.06$ & 0.774 & & & \\
\hline Cardiac arrest & 7.23 & $1.82-28.67$ & 0.005 & 5.00 & $0.46-53.3$ & 0.182 \\
\hline IABP & 4.21 & $1.08-16.37$ & 0.038 & 3.73 & $0.53-26.07$ & 0.183 \\
\hline Initial LVEF & 0.31 & $0.01-77.24$ & 0.678 & & & \\
\hline Coronary stenosis $>50 \%$ & 0.04 & $0.01-7.98$ & 0.533 & & & \\
\hline LVEF at discharge & 1.47 & $0.01-4,878.61$ & 0.925 & & & \\
\hline$\Delta \mathrm{EF}$ & 19.25 & $0.01-36.961$ & 0.443 & & & \\
\hline Malignancy & 3.09 & $0.97-9.82$ & 0.056 & 4.77 & $1.02-22.17$ & 0.046 \\
\hline Diabetes mellitus & 1.45 & $0.43-4.83$ & 0.544 & & & \\
\hline Troponin I peak & 1.02 & $1.01-1.03$ & 0.001 & 1.00 & $0.98-1.02$ & 0.897 \\
\hline BNP peak & 1.00 & $1.00-1.00$ & 0.949 & & & \\
\hline Leukocyte peak & 1.08 & $1.04-1.12$ & 0.001 & 1.10 & $1.03-1.19$ & 0.006 \\
\hline CRP peak & 1.00 & $1.002-1.014$ & 0.013 & & & \\
\hline Apical form & 1.35 & $0.29-6.22$ & 0.698 & & & \\
\hline Mental trigger & 0.42 & $0.05-3.29$ & 0.412 & & & \\
\hline Physical stressor & 1.23 & $0.38-3.93$ & 0.724 & & & \\
\hline Past tobacco use & 1.16 & $0.31-4.40$ & 0.819 & & & \\
\hline
\end{tabular}

$\mathrm{Cl}$, confidence interval; HR, hazard ratio; IABP, intra-aortic balloon pump; LVEF, left ventricular ejection fraction. Other abbreviations as in Tables 1,2.

\begin{tabular}{|c|c|c|c|c|c|c|}
\hline & HR & $95 \% \mathrm{Cl}$ & $P$ value & HR & $95 \% \mathrm{Cl}$ & $P$ value \\
\hline Age & 1.01 & $0.98-1.04$ & 0.286 & & & \\
\hline Female & 0.98 & $0.46-2.06$ & 0.960 & & & \\
\hline Cardiac arrest & 5.80 & $2.72-12.39$ & 0.001 & 6.68 & $2.47-18.01$ & $<0.001$ \\
\hline IABP & 2.42 & $1.06-5.53$ & 0.035 & 1.60 & $0.53-4.79$ & 0.395 \\
\hline Initial LVEF & 0.01 & $0.00-0.39$ & 0.009 & 0.13 & $0.02-8.41$ & 0.341 \\
\hline Coronary stenosis $>50 \%$ & 1.53 & $0.54-4.30$ & 0.419 & & & \\
\hline LVEF at discharge & 0.16 & $0.00-15.84$ & 0.436 & & & \\
\hline$\Delta \mathrm{EF}$ & 26.92 & $0.55-131$ & 0.097 & & & \\
\hline Malignancy & 2.77 & $1.48-5.17$ & 0.002 & 2.62 & $1.26-5.44$ & 0.010 \\
\hline Diabetes mellitus & 1.30 & $0.66-2.56$ & 0.442 & & & \\
\hline Troponin I peak & 1.01 & $1.00-1.02$ & 0.002 & 0.99 & $0.97-1.05$ & 0.175 \\
\hline BNP peak & 1.00 & $1.00-1.01$ & 0.007 & & & \\
\hline Leukocyte peak & 1.05 & $1.03-1.08$ & $<0.001$ & 1.05 & $1.01-1.08$ & 0.008 \\
\hline CRP peak & 1.00 & $1.03-1.09$ & $<0.001$ & & & \\
\hline Apical form & 1.40 & $0.58-3.35$ & 0.442 & & & \\
\hline Mental trigger & 0.62 & $0.24-1.59$ & 0.325 & & & \\
\hline Physical stressor & 2.12 & $1.10-4.10$ & 0.025 & 1.13 & $0.48-2.63$ & 0.776 \\
\hline Past tobacco use & 1.07 & $0.52-2.20$ & 0.850 & & & \\
\hline
\end{tabular}

Abbreviations as in Tables 1-3.

signaling pathway, ${ }^{15}$ suggesting possible synergistic effects of stress and inflammation in the pathogenesis of takotsubo cardiomyopathy in cancer patients.

Our current findings of higher peak leukocyte counts and higher CRP levels in patients with malignancy compared with those without expands our previous work indicating that these inflammatory markers may be involved in the pathogenesis of takotsubo cardiomyopathy. ${ }^{16}$ In particular, our new data suggested that the presence of malignancy may promote inflammation, which in turn contributes to myocyte damage. Furthermore, as the levels of CRP in the patients with cancer were higher at baseline, at peak and at discharge, it is reasonable to speculate that a sustained enhanced inflammatory status associated with malignancy may promote the onset of takotsubo cardiomyopathy. The presence of intramyocardial inflammatory activation in patients with takotsubo cardiomyopathy has been documented directly by myocardial biopsy studies, ${ }^{11}$ as well as by technetium pyrophosphate imaging ${ }^{17}$ and by cardiac MRI. ${ }^{18}$ Of note, recent cardiac MRI data show that takotsubo cardiomyopathy is characterized by a state of intramyocardial edema secondary to a global LV inflammatory response, which is detectable early after the index event and persisting well beyond the resolution of segmental LV contractile dysfunction. ${ }^{19}$

Several additional mechanisms may underlie the relationship 
between inflammatory response, neurohumoral activation, and myocardial damage observed in patients with takotsubo cardiomyopathy and malignancy. Cytokines and reactive oxygen species released by activated inflammatory cells could contribute directly to myocardial damage. ${ }^{20}$ In rats, immobilization stress induces the production of heat shock protein 70 by the myocardium, a potent activator of the inflammatory response, ${ }^{21}$ and enhances atrial and B-type natriuretic peptide expression. ${ }^{22}$ Notably, catecholamines may promote an acute inflammatory response and leukocytosis. Consistent with this effect, we have previously shown a direct relationship between catecholamines and leukocyte levels in the acute phase of takotsubo cardiomyopathy. ${ }^{16}$

The high prevalence of malignancy in patients with takotsubo cardiomyopathy observed in the present cohort is in line with previous data from our group ${ }^{16,23}$ and from Burgdorf and coworkers. ${ }^{5,6}$ However, in a large international collaborative meta-analysis Pelliccia and coworkers reported a lower average prevalence of $10 \%$, with a range from $4 \%$ to $29 \% .^{23}$ This difference may be related, at least in part, to underreporting of a diagnosis of malignancy in patients hospitalized in a cardiology setting. The patients enrolled in the current study were admitted to both the cardiology unit and the critical care department with a large proportion of oncologic patients. Independent of the explanation, the elevated rate of malignancy observed in patients with takotsubo cardiomyopathy greatly exceeds the expected prevalence of cancer in age-matched populations in the United States (8.2\%), Germany (11.2\%) and combined European countries (7.8\%). ${ }^{5,6}$ In France, data from the FRANCIM (French network of cancer registries) registry indicated a total prevalence of cancer of $6.4 \%$ for men and $5.3 \%$ for women. A high prevalence of malignancy in takotsubo cardiomyopathy has also been reported by El-Sayed and coworkers in large cohort of 24,701 patients. ${ }^{24}$ In that study, the prevalence of malignancy was $14.4 \%$ in patients with takotsubo cardiomyopathy, compared with $10 \%$ and $8.8 \%$ in age-matched controls with myocardial infarction and orthopedic conditions, respectively. ${ }^{24}$

\section{Predictors of Death in Takotsubo Cardiomyopathy}

Although previous retrospective studies of patients with takotsubo cardiomyopathy have suggested a significant mortality risk mostly in the early period $(1-1.5 \%)$, with a low risk for recurrence or permanent damage, ${ }^{25}$ and survival rates similar to age- and sex-matched populations, ${ }^{26}$ recent data have challenged this notion. ${ }^{27}$ In our cohort, cardiac death occurred in $7.8 \%$ of the patients, and all-cause death in $26.6 \%$, with higher rates observed in the malignancy subgroup. In-hospital death $(16.2 \%)$ was twice as high as recently reported by another French group (7.5\%). ${ }^{28}$ Patient's severity was also clearly highlighted by the high rates of initial cardiac arrest (8.4\%) and of IABP implantation (10.3\%). Recent investigations have demonstrated that the development of hypotension in the early stages of takotsubo cardiomyopathy is not associated with the degree of LV systolic dysfunction and heart rate, suggesting that other factors are the underlying determinants of the hemodynamic impairment. ${ }^{29}$ The evidence in our cohort of a lack of a relationship between initial LVEF and cardiac death further supports the concept that the extent of myocardial stunning is not a predictor of cardiac death per se, and may represent a protective mechanism in the presence of a stressor event. Although elucidation of the complex interactions between inflammation and malignancy is beyond the scope of the present study, both parameters remained independent predictors of all-cause death and cardiac death. The present findings are consistent with recent reports from Japanese investigators that showed higher in-hospital mortality rates, the deleterious impact of malignancy and inflammation on in-hospital mortality rates, ${ }^{30}$ and the value of the leukocyte count and BNP level as independent predictors of death. ${ }^{31}$

\section{Study Limitations}

We based the diagnosis of takotsubo cardiomyopathy on new criteria proposed by Madias rather the Mayo Clinic's criteria. However, the main difference relies on the recognition that takotsubo cardiomyopathy may occur in a variety of illness, including pheochromocytoma, acute coronary syndrome or intracranial bleeding, and it is unlikely to have significantly affected the overall characteristics of the cohort included in this study. As with similar evaluations of registry data, there are inherent limitations in this type of study, mainly related to known or unknown confounding factors. Inflammation evaluation was restricted to CRP and leukocyte measurements. Other parameters reflecting catecholamine release were not assessed. The effect of LV outflow tract obstruction on the extent of takotsubo could not be established. Owing to the retrospective nature of the study, mechanistic insights concerning the link between malignancy, adrenoceptor sensitivity and inflammation could not be investigated. Events were not adjudicated by an independent committee. Given the relatively low number of cardiovascular deaths recorded in this registry, the multivariate analysis should be interpreted with caution and the findings viewed as exploratory and/or hypothesis generating. Finally, the effect of other factors contributing to adverse outcome, such as unhealed cancer, chemotherapy, radiation and surgery, was not investigated.

\section{Conclusions}

In the present patients with takotsubo cardiomyopathy, the prevalence of malignancy was high and may have affected cardiovascular outcomes through the activation of inflammatory and neurohormonal mechanisms. Further study is necessary to confirm our findings in a large, multicenter cohort and to elucidate the mechanisms underlying the association between malignancy and takotsubo cardiomyopathy.

\section{Conflicts of Interest}

None.

\section{References}

1. Scantlebury DC, Prasad A. Diagnosis of Takotsubo cardiomyopathy. Circ J 2014; 78: 2129-2139.

2. Ghadri JR, Ruschitzka F, Luscher TF, Templin C. Takotsubo cardiomyopathy: Still much more to learn. Heart 2014; 100: 1804-1812.

3. Madias JE. Why the current diagnostic criteria of Takotsubo syndrome are outmoded: A proposal for new criteria. Int J Cardiol 2014; 174: 468-470.

4. Sharkey SW, Maron BJ. Epidemiology and clinical profile of Takotsubo cardiomyopathy. Circ J 2014; 78: 2119-2128.

5. Burgdorf C, Kurowski V, Radke PW. Long-term prognosis of transient left ventricular ballooning syndrome and cancer. Heart Lung 2011; 40: 472 .

6. Burgdorf C, Kurowski V, Bonnemeier H, Schunkert H, Radke PW. Long-term prognosis of the transient left ventricular dysfunction syndrome (Tako-Tsubo cardiomyopathy): Focus on malignancies. Eur J Heart Fail 2008; 10: 1015-1019.

7. Burgdorf C, Nef HM, Haghi D, Kurowski V, Radke PW. Tako-tsubo (stress-induced) cardiomyopathy and cancer. Ann Intern Med 2010; 152: $830-831$.

8. Cimarelli S, Sauer F, Morel O, Ohlmann P, Constantinesco A, Imperiale A. Transient left ventricular dysfunction syndrome: Patho-physiological bases through nuclear medicine imaging. Int J Cardiol 2010; 144: 212-218.

9. Paur H, Wright PT, Sikkel MB, Tranter MH, Mansfield C, O'Gara 
$\mathrm{P}$, et al. High levels of circulating epinephrine trigger apical cardiodepression in a beta2-adrenergic receptor/Gi-dependent manner: A new model of Takotsubo cardiomyopathy. Circulation 2013; 126: 697-706

10. Lyon AR, Rees PS, Prasad S, Poole-Wilson PA, Harding SE. Stress (Takotsubo) cardiomyopathy: A novel pathophysiological hypothesis to explain catecholamine-induced acute myocardial stunning. Nat Clin Pract Cardiovasc Med 2008; 5: 22-29.

11. Nef HM, Mollmann H, Elsasser A. Tako-tsubo cardiomyopathy (apical ballooning). Heart 2007; 93: 1309-1315.

12. Joseph T, Olivier B, Magnier S, Brugieres L, Casasoprana A. Cardiomyopathy induced by catecholamines in neuroblastoma. Arch Pediatr 1997; 4: 32 - 35 (in French).

13. Rosti L, Festa P, Corbetta C. Rapid reversal of dilated cardiomyopathy following removal of neuroblastoma. Cardiol Young 1999; 9: 519-521.

14. Arabacilar P, Marber M. The case for inhibiting p38 mitogen-activated protein kinase in heart failure. Front Pharmacol 2015; 6: 102.

15. Land S, Niederer SA, Louch WE, Roe AT, Aronsen JM, Stuckey DJ, et al. Computational modeling of Takotsubo cardiomyopathy: Effect of spatially varying beta-adrenergic stimulation in the rat left ventricle. Am J Physiol Heart Circ Physiol 2014; 307: H1487-H1496.

16. Morel O, Sauer F, Imperiale A, Cimarelli S, Blondet C, Jesel L, et al. Importance of inflammation and neurohumoral activation in Takotsubo cardiomyopathy. J Card Fail 2009; 15: 206-213.

17. Ito K, Sugihara H, Katoh S, Azuma A, Nakagawa M. Assessment of Takotsubo (ampulla) cardiomyopathy using $99 \mathrm{mTc}$-tetrofosmin myocardial SPECT--comparison with acute coronary syndrome. Ann Nucl Med 2003; 17: 115-122.

18. Eitel I, Lucke C, Grothoff M, Sareban M, Schuler G, Thiele H, et al. Inflammation in takotsubo cardiomyopathy: Insights from cardiovascular magnetic resonance imaging. Eur Radiol 2010; 20: 422-431.

19. Neil CJ, Nguyen TH, Sverdlov AL, Chirkov YY, Chong CR, Stansborough J, et al. Can we make sense of takotsubo cardiomyopathy? An update on pathogenesis, diagnosis and natural history. Expert Rev Cardiovasc Ther 2012; 10: 215-221.

20. Singal PK, Kapur N, Dhillon KS, Beamish RE, Dhalla NS. Role of free radicals in catecholamine-induced cardiomyopathy. Can $J$ Physiol Pharmacol 1982; 60: 1390-1397.

21. Ueyama T. Emotional stress-induced Tako-tsubo cardiomyopathy: Animal model and molecular mechanism. Ann NY Acad Sci 2004; 1018: $437-444$.

22. Nef HM, Mollmann H, Hilpert P, Hamm C, Elsasser A. Tako-Tsubocardiomyopathy. Dtsch Med Wochenschr 2008; 133: 1629-1636; quiz 1637-1640 (in German).
23. Pelliccia F, Parodi G, Greco C, Antoniucci D, Brenner R, Bossone E, et al. Comorbidities frequency in takotsubo syndrome: An international collaborative systematic review including 1,109 patients. $A m$ J Med 2015; 128: 654.e11-e.19.

24. El-Sayed AM, Brinjikji W, Salka S. Demographic and co-morbid predictors of stress (takotsubo) cardiomyopathy. Am J Cardiol 2012; 110: $1368-1372$.

25. Wittstein IS, Thiemann DR, Lima JA, Baughman KL, Schulman SP, Gerstenblith G, et al. Neurohumoral features of myocardial stunning due to sudden emotional stress. N Engl J Med 2005; 352: 539-548.

26. Elesber AA, Prasad A, Lennon RJ, Wright RS, Lerman A, Rihal CS. Four-year recurrence rate and prognosis of the apical ballooning syndrome. J Am Coll Cardiol 2007; 50: 448 -452.

27. Templin C, Ghadri JR, Diekmann J, Napp LC, Bataiosu DR, Jaguszewski $\mathrm{M}$, et al. Clinical features and outcomes of takotsubo (stress) cardiomyopathy. N Engl J Med 2015; 373: 929-938.

28. Coupez E, Eschalier R, Pereira B, Pierrard R, Souteyrand G, Clerfond $\mathrm{G}$, et al. A single pathophysiological pathway in Takotsubo cardiomyopathy: Catecholaminergic stress. Arch Cardiovasc Dis 2014; 107: $245-252$

29. Chong CR, Neil CJ, Nguyen TH, Stansborough J, Law GW, Singh $\mathrm{K}$, et al. Dissociation between severity of takotsubo cardiomyopathy and presentation with shock or hypotension. Clin Cardiol 2013; 36: $401-406$.

30. Isogai $\mathrm{T}$, Yasunaga $\mathrm{H}$, Matsui $\mathrm{H}$, Tanaka $\mathrm{H}$, Ueda $\mathrm{T}$, Horiguchi $\mathrm{H}$, et al. Out-of-hospital versus in-hospital Takotsubo cardiomyopathy: Analysis of 3719 patients in the Diagnosis Procedure Combination database in Japan. Int J Cardiol 2014; 176: 413-417.

31. Murakami T, Yoshikawa T, Maekawa Y, Ueda T, Isogai T, Konishi $\mathrm{Y}$, et al. Characterization of predictors of in-hospital cardiac complications of takotsubo cardiomyopathy: Multi-center registry from Tokyo CCU Network. J Cardiol 2014; 63: 269-273.

\section{Supplementary Files}

Supplementary File 1

Figure S1. $\mathrm{N}=21,326$ coronary angiography between May 2008 and December 2014 (1,754 in 2008 / 2,752 in 2009 / 2,887 in 2010 / 3,207 in 2011 / 3,512 in 2012 / 3,468 in 2013/3,746 in 2014).

Table S1. Types of malignancy in takotsubo patients

Table S2. Identifiable precipitating factors of takotsubo patients

Please find supplementary file(s);

http://dx.doi.org/10.1253/circj.CJ-16-0388 